\title{
Understanding Motivations for Volunteering in Food Insecurity and Food Upcycling Projects
}

\author{
Sabrina Rondeau ${ }^{1, *(\mathbb{D}}$, Sara M. Stricker ${ }^{2}\left(\mathbb{D}\right.$, Chantel Kozachenko $^{3}$ and Kate Parizeau ${ }^{3}(\mathbb{C}$ \\ 1 School of Environmental Sciences, University of Guelph, Guelph, ON N1G 2W1, Canada \\ 2 Department of Plant Agriculture, University of Guelph, Guelph, ON N1G 2W1, Canada; \\ strickes@uoguelph.ca \\ 3 Department of Geography, Environment and Geomatics, University of Guelph, Guelph, ON N2L 3G1, \\ Canada; kozachec@uoguelph.ca (C.K.); kparizea@uoguelph.ca (K.P.) \\ * Correspondence: srondeau@uoguelph.ca
}

Received: 25 January 2020; Accepted: 6 March 2020; Published: 11 March 2020

\begin{abstract}
For non-profit organizations relying on volunteers to operate, investigations into the motivations of volunteerism are critical to attract new volunteers and to support the current ones. This study looked at volunteerism in the not-for-profit project The SEED in Ontario, Canada, which is looking to address food insecurity through a new social enterprise project that will create value-added "upcycled" products from second-grade produce while offering training opportunities for youth facing barriers to employment. The aims of this paper were to explore why volunteers chose to offer their time to this project and to gauge the current volunteers' interest in volunteering with the organization's new "Upcycle Kitchen". Thirty-seven volunteers responded to a self-administered survey. They reported altruism, self-development, and social life improvement as their main motivations for volunteering. The volunteers expressed enthusiasm toward the Upcycle Kitchen initiative, which seems to be attributable to the multidimensional, creative, and educational aspects of the project. Tackling food insecurity and reducing the environmental impact of food waste are values which would most likely influence the respondents' willingness to volunteer in food upcycling activities. We believe that this study is a good model to learn about the many facets of volunteerism for social enterprises developing upcycling-based food projects.
\end{abstract}

Keywords: volunteer; social enterprise; food insecurity; food waste; food rescue

\section{Introduction}

While one in eight households in Canada struggle to put food on the table, over $\$ 49.5$ billion worth of food is wasted annually along the Canadian food value chain, accounting for nearly one third of the food produced in Canada (Gooch et al. 2019). According to national estimates, $12 \%$ of Canadian households experienced some level of food insecurity in 2014 (Tarasuk et al. 2016). By gathering food that could have otherwise been wasted and redirecting it for human consumption, food rescue provides critical opportunities to concurrently address food insecurity and reduce food waste (Hecht and Neff 2019). Although food rescue may sometimes be regarded as being a temporary solution to food insecurity or waste (Mirosa et al. 2016; Reynolds et al. 2015), food rescue organizations still play an important role in connecting available food to those who need it (Hecht and Neff 2019; Hoyos and Angel-Urdinola 2019; Mirosa et al. 2016). Much of the food rescued by large organizations such as food banks and food pantries is shelf-stable (Chapnick et al. 2019). However, some of the most nutritious food, such as fruits and vegetables, is perishable and may require being rescued by smaller charitable organizations which then have to deal with the additional challenge of food expiry dates (Bierma et al. 2019; Mirosa et al. 2016). Food rescue may occur as second harvests on 
the farm, surplus produce at the grocery store, or leftover food from restaurants (Gooch et al. 2019; Mousa and Freeland-Graves 2017b; Sedlmeier et al. 2019). The rescued food may be distributed for free, sold at a reduced fee at social marketplaces, or upcycled into new products (Gooch et al. 2019; Sedlmeier et al. 2019). Current research in food insecurity is focused on the stability of these services and how to reduce stigma and improve the dignity for the clients which access these services (Bedore 2018; Booth et al. 2018; Gordon et al. 2018; McKay et al. 2018; Roy et al. 2017).

Upcycling, sometimes referred to as value-added processing, is a growing trend in the food industry, as the focus shifts towards more sustainable food alternatives (Bhatt et al. 2018; O'Donnell et al. 2015; ReFED 2016). To circumvent the losses due to food expiry dates, the usable life of donated foods can be extended through processing methods such as pickling, canning, freezing, or making soups, sauces or other value-added products (ReFED 2016). In some cases, rescued food may be visually undesirable, or cannot be directly consumed (Bhatt et al. 2018; Laufenberg et al. 2003). Rescued food could also be by-products from food processors (Laufenberg et al. 2003). This rescued food can be used as ingredients to create new products for human or animal consumption, or other strategies can be implemented that divert these organics from landfill (Laufenberg et al. 2003). These innovations range from biofuel to fruit juice, and many things in between (O'Donnell et al. 2015; ReFED 2016). There are several projects that aim to turn surplus and rescued food into marketable products (Hecht and Neff 2019; ReFED 2016). The branding and marketing of these products often focuses on the environmental impacts, such as reduced tonnage sent to landfill, reduced emissions, and reduced chemical inputs (O’Donnell et al. 2015; ReFED 2016; Reynolds et al. 2015).

Food rescue organizations may operate under either a charity or social enterprise model (Mirosa et al. 2016; Sedlmeier et al. 2019). Food rescue charitable organizations, which include food banks and food-sharing operations, acquire donated food and make it available to those in need (Nikkel et al. 2019; Riches 2018; Sedlmeier et al. 2019). In the food rescue space, social enterprises include community supermarkets or other food-related social initiatives which sell donated food at significantly reduced prices or use it in products that are sold as a profit (McKay et al. 2018; Sedlmeier et al. 2019). These business models differ from charities since they accumulate financial profits, which can then be funneled into additional services or mandates (Holweg and Lienbacher 2011; Staicu 2018). There is some evidence to suggest that a social enterprise model could provide additional stability to food insecurity organizations (Paget 2015; Popielarski and Cotugna 2010; Wills 2017), which are largely reliant on grants and donors. These important distinctions between charity and social enterprise models may influence volunteer experiences as well as their perceptions of the value of the projects they are supporting (Zappalà 2001).

Food service organizations are one of the main sites of volunteerism reported by volunteers in Canada (Sinha 2015). The centrality of volunteerism to many social enterprise models suggests that volunteer recruitment and retention are likely a key aspect of commercial viability (Wills 2017). In a qualitative study regarding the challenges of the non-profit and voluntary organizations in Canada, participants reported having experienced a decline in the number of volunteers with direct impact on their delivery of programs and services (Hall et al. 2003). Other common challenges faced by food rescue businesses include low staff motivation and high volunteer turnovers, which can lead to substantial investment of time in training and re-creating relationships (Hecht and Neff 2019; Otten et al. 2018). Therefore, investigations into the motivations of volunteerism in both non-profit organizations and social enterprises are critical to attract new volunteers and to support the current ones (Hibbert et al. 2003; Mirosa et al. 2016).

This study looked at volunteerism in a community food project which addresses food insecurity in Ontario, Canada. The SEED is a not-for-profit food project at the Guelph Community Health Centre that was established in 2015. As is increasingly common with organizations working in this sector, The SEED combines non-profit and social enterprise models in its initiatives in order to diversify its funding sources and cross-subsidize projects with different funding models. They work to increase physical and financial access to nutritious foods to community members by hosting sliding-scale priced 
community food markets, selling discounted bulk vegetable boxes, leading food literacy projects, distributing food to emergency food providers, and teaching farming skills to local youths. Volunteers with The SEED participate in fundraisers which sell pre-packaged soup mixes, assist at the market or farm, and help run food nutrition programs. Using the social enterprise model, The SEED's newest project is looking to address food insecurity by using food that would have otherwise gone to waste to create value-added "upcycled" products, while offering training opportunities for youth facing barriers to employment. By recovering and revalorizing food that would have otherwise been wasted, the Upcycle Kitchen aims to reduce the stigma associated with consuming surplus food, prevent the environmental harm caused by the disposal of avoidable food waste, and address social goals of improving income security for underemployed youth.

The focus of this paper was to explore why volunteers chose to offer their time to the SEED. More precisely, this research aimed to (1) evaluate the recruitment and retention of volunteers in the organization; (2) explore the motivations and benefits of volunteering for the volunteers who became involved with the project in the first place; and (3) gauge the current volunteers' interests in the new Upcycle Kitchen project, which will be launched in the near future. The survey results will have the dual impact of providing an inventory for The SEED to assess their volunteering needs and current levels of volunteer satisfaction, as well as fostering an understanding of volunteer recruitment needs for future social enterprises focusing on food rescue.

We expect that more social enterprises focusing on upcycling-based food projects will be created in the near future (ReFED 2016) and we believe that this study is a good model to learn about the many facets of volunteerism in such organizations. Because of the small scale of the project, The SEED depends heavily on volunteers to maintain their core operations. Considering the multidimensional nature of the project, it is important to understand the motivations of the volunteers as it would help define which value proposition should be featured through recruitment efforts. Compared with the more traditional charity model of volunteerism, very little is known about the perceptions of the project values volunteers in social enterprises are supporting. Understanding such perceptions is a key aspect for recruitment and retention.

\section{Overview of the Literature on Social Enterprises and Volunteering}

Recently, there has been an increase in the development and recognition of social enterprises as models for addressing social issues in North America (Bacq and Janssen 2011). This increase may be due to an increasing trend of promoting social goals and the social responsibility of individuals and businesses (Dees 1998; Hoyos and Angel-Urdinola 2019). Some social enterprises provide personal care services, involve arts and creativity to support individuals, address employment issues through work integration, or focus on community development (Roy et al. 2014). In recent years, several social enterprises have shifted towards addressing the marginalization of individuals who experience barriers to full social participation and are working to reduce stigma directed towards this demographic (Lysaght et al. 2012). These social enterprises may aim to help by providing meaningful work, creating a safe and supportive environment, cultivating knowledge and skills, expanding social networks, and building trust and cooperation (Roy et al. 2017). In addition, they may also act by increasing access to information and working to improve public awareness and understanding of social issues (Roy et al. 2017).

The definition of social enterprise continues to be debated. Some describe social enterprises as socially responsible commercial businesses with cross-sector partnerships (Sagawa and Segal 2000), while others portray them as ways to alleviate social problems and initiate social change (Alvord et al. 2004). A social entrepreneurship could be classified as a not-for-profit organization with unconventional funding strategies or systems to create social value (Austin et al. 2003). In the province of Ontario, Canada, the government defines a social enterprise as "an organization that uses business strategies to maximize its social or environmental impact" (Government of Ontario 2013). 
This new terminology is important since it suggests blurring the boundaries between businesses and not-for-profit ventures.

In the context of this study, we are also interested in the sustainability of the food system from the viewpoint of food-insecure individuals. The social enterprise components of these organizations aim to make food charity programs more economically sustainable and may help to develop relationships and partnerships with other organizations (Luke and Chu 2013). Innovative solutions provided by social enterprise organizations can reduce the pressure on emergency food agencies and relieve some of the demand for their services (Popielarski and Cotugna 2010). The mandate of food-related social enterprises may be to raise awareness, provide training and employment, or offer services or food at discounted prices to participants from marginalized communities (Bedore 2018; Berno 2017; Dennis et al. 2017; Evans et al. 2012). Some examples of social enterprises addressing food insecurity internationally include community supermarkets (Hustinx and Waele 2015; Paget 2015), urban agriculture initiatives (Berno 2017; Dimitri et al. 2016), and food rescue operations (Mirosa et al. 2016; Nikkel et al. 2019).

Over the last two decades, a rich body of literature on volunteerism has emerged, either focusing on the characterization and recruitment of volunteers or the motivations and benefits of volunteering (Brewis et al. 2010; Bussell and Forbes 2006; Demir et al. 2019; Wilson 2012). Among others, the Volunteer Functions Inventory developed by Clary et al. $(1992,1998)$ has been widely used to describe the motivations of volunteers (Mousa and Freeland-Graves 2017a; Demir et al. 2019; Wu et al. 2009). This survey instrument considers six potential motivations for volunteering: values (altruism), understanding (learning new skills), social (developing relationships), career (career benefits obtained by volunteering), protective (to protect the ego or dispel negative feelings), and enhancement (personal growth and self-esteem). Drawing on Clary et al. (1998) functional approach, a previous study indicated that the volunteers from food redistribution organizations such as food pantries and churches were highly motivated by feelings of altruism and opportunities for career and social life improvement (Mousa and Freeland-Graves 2017a).

Zappalà (2001) suggests a number of differences between a more traditional charity model and a social enterprise model of volunteering, based on observations from Australia. This typology suggests that charity volunteers are usually middle-aged or older women who are not employed and have fewer skills. Their main motivation for volunteering is altruism, and their loyalty to the organization is important. These volunteers tend to work on specialized tasks on site and may be seen as less skilled than employed staff in the organization. In contrast, social enterprise volunteers are hypothesized to be young, highly skilled, and employed full-time. They may have skills and experience that surpass those of the organization's paid staff. They value altruism, but also seek personal or corporate gains (on behalf of their employers). They are described as fixed-term volunteers whose on-going commitment to the organization is less important than traditional volunteers. If these distinctions between types of volunteers exist in the Canadian context, they will have implications for volunteer recruitment, training, management, and recognition (Warburton et al. 2004). It has also been posited that changes in funding models have led to a shift toward more professionalization of volunteers and a reduced need for charity model volunteers more broadly (Warburton et al. 2004). Such shifts would similarly require changes in volunteer engagement and management.

Reynolds et al. (2015) note that food rescue is an under-studied phenomenon, particularly in terms of its commercial viability. Little work has been published on the experiences of volunteers in social enterprise projects, particularly in food rescue organizations (see Hibbert et al. 2003; Mirosa et al. 2016 for exceptions). More needs to be understood about the experiences, values, and personal skills of potential volunteers if social enterprise organizations are to successfully recruit and retain individuals for their food-upcycling activities, in particular. We argue that such research is much needed, as it would address a research gap regarding the experiences of volunteers in social enterprise projects which address food insecurity and social dignity. 


\section{Materials and Methods}

\subsection{Data Collection}

A confidential self-administered survey questionnaire including multiple-choice and open-ended questions was disseminated to all former and current volunteers of The SEED by the project's Volunteer Coordinator. The volunteers were given 10 days (17-26 April 2019) to respond to the survey, and as an added incentive, were given the option to enter in a random draw to win a $\$ 20$ gift certificate. A total of 37 volunteers (aged 18+) participated in the study. The survey was circulated to approximately 100 volunteers (all current and former volunteers of The SEED), suggesting our response rate was $\sim 37 \%$. Approval for this study was granted by the Research Ethics Board of the University of Guelph (REB \#19-03-005).

\subsection{Survey Questionnaire}

The survey questionnaire (Supplementary file 1) consisted of four sections. The first section contained questions about the volunteers' level of involvement with the project (status, frequency, and duration of volunteer activities), mode of recruitment, and occupational status. The questions were designed to capture demographic data without being specific enough to identify individuals. The second section included questions assessing personal motivations for volunteering. The overarching motivations assessed in this study were based on the Volunteer Functions Inventory developed by Clary et al. (1998) and results from Mousa and Mousa and Freeland-Graves (2017a). The third section included questions assessing volunteers' perception of the proposed "Upcycle Kitchen" project and self-reported personal skills that volunteers could bring to the project. The fourth and final section assessed the perceived benefits of the volunteering experience and gathered recommendations for The SEED to improve the volunteering experience. The third and fourth sections were designed in collaboration with the project's coordinator to capture elements deemed valuable for volunteer recruitment and retention.

A three-point Likert scale (most important, somewhat important, not important) was used to assess the motivations of volunteers and willingness to participate in the new project. All other questions were multiple-choice items. Open-ended questions were included in all four sections, which prompted respondents to elaborate their motivations, their opinion about the Upcycle Kitchen, or any opinions that were not captured by the multiple-choice questions (Vecina and Marzana 2019).

\subsection{Analyses}

Data were analyzed using the $\mathrm{R}$ software ( $\mathrm{R}$ Core Team 2016). $\mathrm{R} \times \mathrm{c}$ contingency tables were used to assess differences between motivations of volunteers and independent variables (status, frequency, and duration of involvement; occupational status; skills improvement) and analyzed with Fisher's exact test followed by pairwise comparisons, when appropriate. Findings were considered significant when $p<0.05$. Additional comparisons were made between (a) occupational status and duration of involvement, recruitment strategy, and skills improvement; (b) frequency of involvement and skills improvement; and (c) duration of involvement and skills improvement. Answers to open-ended questions were thematically coded according to the concepts described in the literature review above (including Brewis et al. 2010; Clary et al. 1992; 1998; Hibbert et al. 2003).

\section{Results}

\subsection{Profile and Recruitment of Volunteers}

Table 1 shows the characteristics and volunteering profile of the respondents. The volunteers learned about volunteering opportunities with The SEED through many modes: mostly from friends or family members who were already involved, through partnership with other organizations, or through the project's website or social media. Most participants were college or university students or were 
currently holding a position of employment. Almost two-thirds of the participants were volunteering regularly at the time of survey completion, most of them on a weekly basis. More than two-thirds of the participants had been volunteering with the project for more than six months. Students were mostly short-term volunteers, but the length of involvement did not significantly differ between the different volunteers' occupational status.

Table 1. Characteristics and profile of the volunteers $(n=37)$ involved in a not-for-profit food project addressing food insecurity issues in Ontario, Canada.

\begin{tabular}{lc}
\multicolumn{1}{c}{ Variables } & Number of Respondents n (\%) \\
\hline Main occupation & $12(32.4)$ \\
College or university student & $10(27.0)$ \\
Employed for wages or self-employed & $9(24.3)$ \\
Retired & $2(5.4)$ \\
Out of work & $1(2.7)$ \\
Family caregiver or homemaker & $0(0.0)$ \\
High school student & $3(8.1)$ \\
Other & \\
Involvement status & $21(56.7)$ \\
Current volunteer/regular basis & $11(29.7)$ \\
Current volunteer/intermittent events & $5(13.5)$ \\
Former volunteer & $13(35.1)$ \\
Duration of involvement & $14(37.8)$ \\
More than one year & $10(27.0)$ \\
Six months to one year & \\
Less than 6 months & $20(54.1)$ \\
Frequency of volunteering activities & $6(16.2)$ \\
Once per week & $11(29.7)$ \\
Once or twice per month & \\
Less than once per month & $12(32.4)$ \\
Mode of recruitment & $9(24.3)$ \\
Family of friends involved with The SEED & $12(32.4)$ \\
Website or social media & $3(8.1)$ \\
Through partnership with another organization & $1(2.7)$ \\
Customer or recipient of the services offered by & \\
The SEED & \\
Flyers/info pamphlets & \\
\hline &
\end{tabular}

\subsection{Motivations of Volunteers}

When participants were asked about their personal motives for volunteering with the project, the main motivations reported were altruism, self-development, and social life improvement (Figure 1). The options available to select were

(1) Altruism: I wish to give my time to help other members of my community;

(2) Self-development: Volunteering is a good way to learn through direct hands-on experience and develop my skills;

(3) Social life: Volunteering benefits my social life (e.g., by meeting new people, being with my friends);

(4) Career improvement: Volunteering can improve my career (e.g., get experience, make new contacts, improve my resume);

(5) Escapism: Volunteering is a good escape from my problems;

(6) Extrinsic rewards: I'm volunteering to fulfill obligation through school, a service requirement or to increase my chance to gain an award, certificate, scholarship or accreditation. 


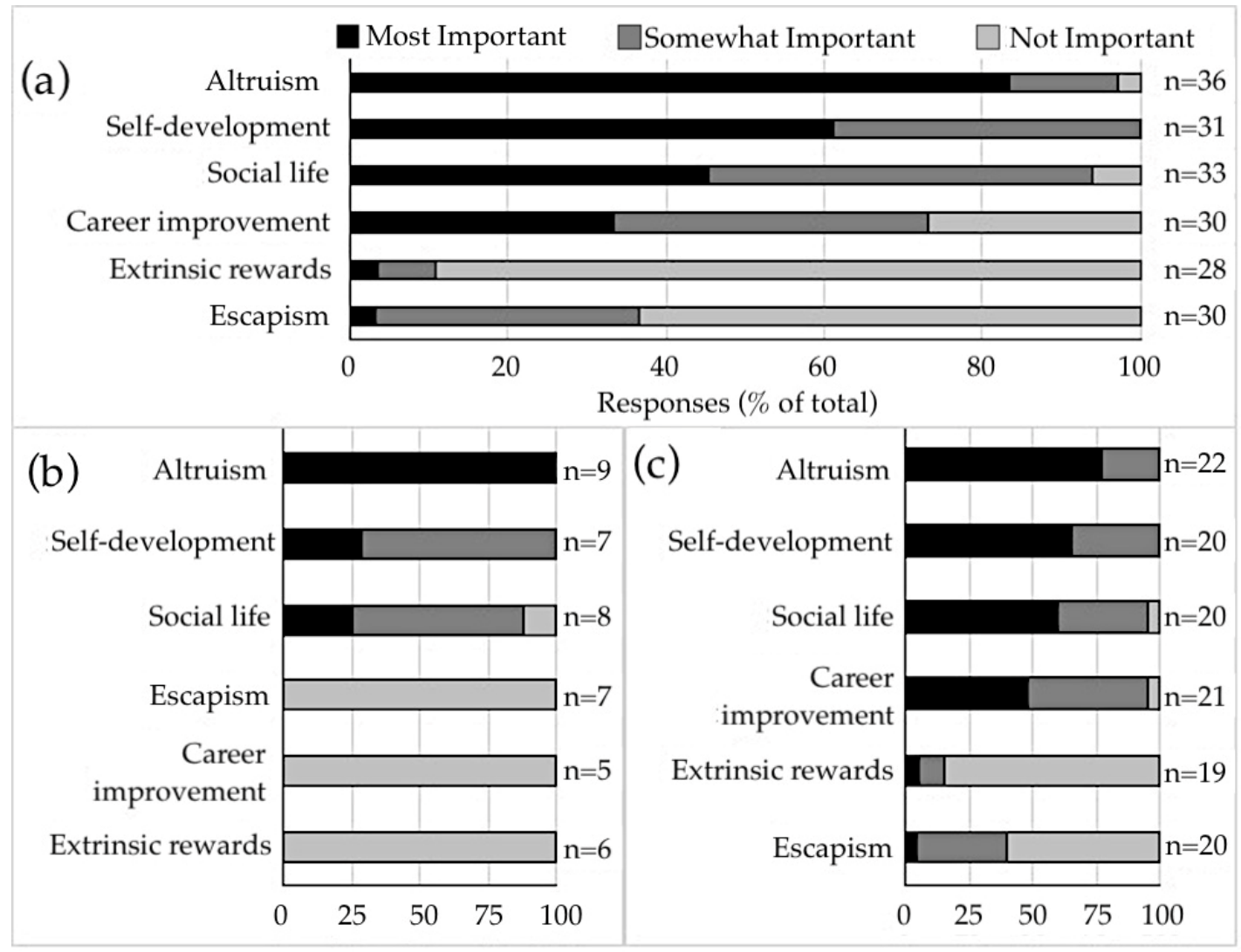

Figure 1. Volunteers' personal motivations to get involved with a not-for-profit food project addressing food insecurity issues, according to the respondent's occupational status: (a) all respondents $(\mathrm{n}=$ $37)$; $(b)$ retirees $(n=9)$; (c) students and paid workers $(n=22)$. Personal motives varied significantly between retirees and those who are either paid workers or students (grouped together) (two-sided Fisher test; $\mathrm{p}=0.0351$ ).

Personal motives tended to vary according to the volunteers' occupational status (Figure $1 \mathrm{~b}, \mathrm{c}$ ) and were significantly different between workers and students (grouped together) and retirees (two-sided Fisher test; $p=0.0351$ ). Career improvement was also an important motive for both students and paid workers, who accounted for two-thirds of the participants. Only three respondents flagged extrinsic rewards as a motive to volunteer; all of them were students. No difference in the volunteers' personal motives was detected in relation to the length of involvement with the project. In addition to the six overarching motivations stated in the survey, twenty-two respondents provided other motives to start their involvement with The SEED. These have been grouped into five additional constructs:

- Personal beliefs in the cause and shared values with the project $(n=7)$

- A strong interest in food policy and/or combatting food insecurity $(n=5)$

- Recognizing food insecurity as a major societal issue $(\mathrm{n}=2)$

- $\quad$ Good fit for the volunteers' lifestyle $(\mathrm{n}=1)$

- Having personally observed food insecurity $(n=1)$

\subsection{Benefits for the Volunteers}

Almost two-thirds of the respondents reported that their interpersonal skills increased following their involvement with the project. When asked to provide an explanation to their response, some volunteers provided comments about the skills they felt have improved. These skills were related to:

- $\quad$ Teamwork and collaboration $(n=5)$ 
- $\quad$ Communication $(\mathrm{n}=4)$

- Self-confidence $(\mathrm{n}=3)$

- Socialization $(\mathrm{n}=3)$

- Open-mindedness $(\mathrm{n}=3)$

- Awareness towards food insecurity issues $(n=2)$

- $\quad$ Experience working with the public $(\mathrm{n}=2)$

- Leadership $(\mathrm{n}=1)$

- Organization and time management $(\mathrm{n}=1)$

Numbers in parentheses correspond to the number of times each skill was reported, as coded from open-ended questions. Respondents further elaborated on the value of interpersonal skill development in the open-ended questions on the survey:

"Interpersonal skills are something that you constantly are working on and improving. Volunteering with The SEED helped especially with communication as you had to explain what the company was doing many times."

"My personal life and work life do not require a lot of collaboration. Volunteering with The SEED has been a good supplement to developing many skills related with working with other people to accomplish a common goal."

"I needed to get back into the community and talk with people. Volunteering has helped me to become better socialized after a period of isolation."

When compared among the different occupational groups, significantly fewer retirees reported an improvement in their skills (one-sided Fisher test; $p=0.0338$ ). Not being in a leadership position, past roles in other volunteering activities, and pre-existent strong interpersonal skills were provided as explanations when no increase of interpersonal skills was reported.

\subsection{Interest of the Volunteers in a Future Project Related to Upcycled Food Products}

Most respondents (25/37) reported that they were inclined to volunteer in the described Upcycle Kitchen activities. Explanations reported for this willingness included environmental consciousness, having experience working in a kitchen or with other food recovery organizations, enjoying the creativity and the novelty of the project, enjoying cooking, and a desire to educate the community about food waste and food insecurity issues. Comments included the following:

"I think that is a fantastic way to help educate people on how to get the most value out of their food. Additionally, preservation methods can be pretty cheap and affordable, and extend the life of a lot of our food."

"I see food waste as being a major problem within the community and would like to assist in ensuring that more of the food we produce is being consumed. If this can be done in a way that also enhances the livelihoods of youth then I am even more on board. I also love to cook and have some experience in canning, so the program fits my interests."

"I have a history of working in a kitchen, and enjoy taking a 'rescue' vegetable home and seeing what can be done with it. I would enjoy the creative element of the upcycle kitchen to see what can be salvaged from donated produce, and how many recipes could be involved. Teamwork to enhance that creativity, and to show others who are less familiar with kitchen skills how to maximize a food item's value, could be a self-confidence boost as well as an important collaboration to strengthen the work of the program." 
Neutral (maybe, don't know) and negative responses regarding respondents' willingness to volunteer with the Upcycle Kitchen were related to challenges regarding availability, working in a standing position for long periods of time, and not living in the local area anymore. One respondent reported not being convinced with the benefits resulting from this project to the community. This volunteer explained that they were "not yet convinced how [the project] will be done in a way that benefits the Community and isn't just a way for business to get rid of food waste".

Tackling food insecurity and reducing the environmental impact of food waste were the values that were the most commonly reported as influencing the respondents' willingness to volunteer in the Upcycle Kitchen activities (Figure 2). Reducing the stigma associated with the consumption of surplus food and creating employment and training opportunities for youth facing barriers to employment were also reported as influencing factors for more than half of the respondents. The latter was more frequently reported by students and paid workers than by retirees, although no significant difference was detected between the influencing factors and the respondents' occupational status. The numerous skills and previous experience of respondents that might be useful to the Upcycle Kitchen project are reported in Table 2.

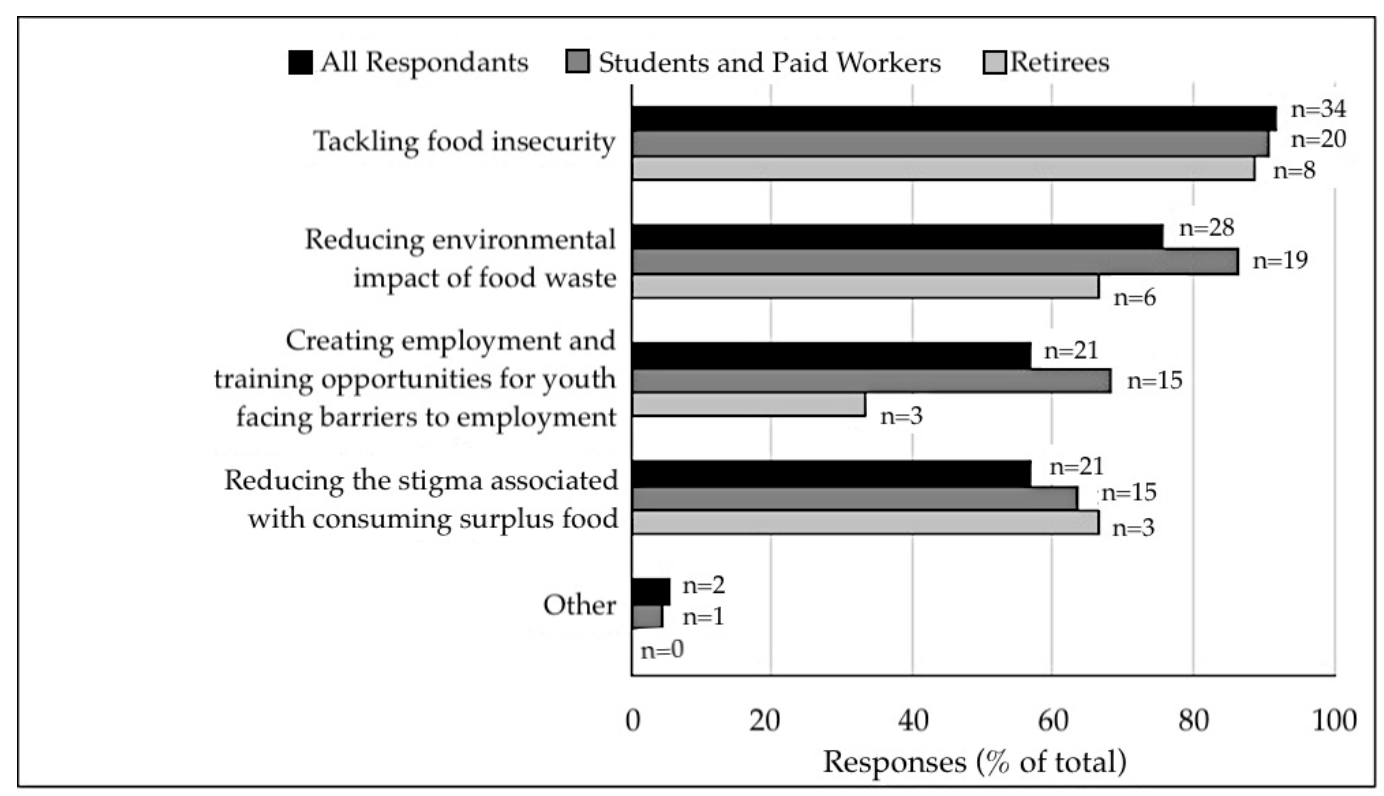

Figure 2. Values reported as the most likely to influence volunteer's willingness to get involved in a new project aiming to process rescued food in value-added products to generate income for food insecure community members for all respondents, $(n=37)$, students and paid workers $(n=22)$, and retirees $(n=9)$. 
Table 2. Self-reported personal skills and experiences of the volunteers $(n=37)$ that are considered useful in upcycling-based food projects and other food recovery programs.

\begin{tabular}{cc}
\hline Personal Skill and Experiences & Number of Respondents n (\%) \\
\hline Enjoying working with the public & $33(89.2)$ \\
Ability to cook & $32(86.5)$ \\
Good planning and time management skills & $30(81.1)$ \\
Experience working in customer service & $30(81.1)$ \\
Experience in employee training & $27(73.0)$ \\
Enjoying working on their feet and staying active & $27(73.0)$ \\
Strong leadership skills & $24(64.9)$ \\
Have, or have had, a first aid certification & $19(51.4)$ \\
Experience working in an industrial or commercial kitchen & $18(48.6)$ \\
Have, or have had, a Safe Food Handler's certificate & $18(48.6)$ \\
Experience driving a truck & $6(16.2)$ \\
\hline
\end{tabular}

\subsection{Retention of Volunteers}

Overall, the respondents reported a positive volunteering experience with the project, which was mainly attributed to the success of The SEED in showing appreciation. Some of the recommendations provided by the respondents for the project to improve the volunteering experience include providing volunteering training opportunities, giving volunteers more responsibilities and leadership opportunities, and updating the volunteers on the impact of the events, programs, and activities led by The SEED.

\section{Discussion}

Our results are consistent with those of several studies reporting that volunteers are motivated to become involved primarily for altruistic reasons (Ahn et al. 2011; Bang and Ross 2009; Brewis et al. 2010; Mousa and Freeland-Graves 2017a). In their Volunteer Functions Inventory, Clary et al. (1992) described altruism as a values function which allows the volunteers to act on profoundly held beliefs about the importance of helping others. By volunteering, people can therefore gain satisfaction by expressing their altruistic values in a way that is meaningful to them. Similarly to our study, Mousa and Mousa and Freeland-Graves (2017a) found that the most prevalent motivator for volunteers in food rescue nutrition was altruism. Giving time for a project that is "in line with [their] values and beliefs" was particularly important for many respondents in the current study. Self-development was the second most important motivation reported. Such a desire to develop personal skills or to learn for the sake of learning has more than once been reported as an important motivation for volunteers, particularly students (Brewis et al. 2010). The combination of a relatively young volunteer group, its interest in self-development in addition to altruistic motives for volunteering, and the skill profile of survey respondents suggest that volunteers at The SEED are similar to Zappalà (2001) typification of social enterprise volunteers. This profile of volunteers highlights the importance of using the skills that volunteers bring to the organization, as well as providing opportunities for them to develop their skills further.

The social aspect of volunteerism was also an important motivator for many volunteers. Volunteering can improve one's social life by providing opportunities to meet new people and form new friendships, to spend more time with one's friends or family, and to develop relationships with staff and other volunteers (Clary et al. 1992; Dennis et al. 2017; Hibbert et al. 2003; Mousa and Freeland-Graves 2017a). Volunteering can also help maintain good mental health and foster a greater sense of community, especially within the elderly population (Warburton and Winterton 2017). Past research has shown that good relationships with other volunteers and staff were correlated with greater satisfaction of volunteer work (Yanagisawa and Sakakibara 2008). Mirosa et al. (2016) study of volunteers in a food rescue social enterprise in New Zealand also highlighted the value of social benefits (alongside altruistic emotional benefits) for volunteers. Moreover, Munoz et al. (2015) note 
that the combination of a work-like environment with social activities ("the hybrid social-economic space") may be a feature of social enterprise contexts that enhances the well-being of volunteers.

Unsurprisingly, career motivation was stronger for students and paid workers, and reported as "not important" by more than half of the retirees. This is in agreement with other studies that reported career concerns to be more important to younger volunteers (Clary et al. 1992). Further volunteering motives often cited in the literature include personal interests, having a leisure experience, religious beliefs, and emotional needs (Brewis et al. 2010; Dennis et al. 2017; Yeung 2004). Additionally, our research found that some volunteers may have personally observed food insecurity, which may also act as a motivator to get involved. Only one respondent specifically mentioned having "observed food security [issues] within the community, on the ground", but it should be noted that this motivator was not explicitly included in the six main motivations prompted in the present study and could be a key source of altruistic feelings for people volunteering in this sector.

Most participants reported benefits to themselves in the form of an increase in personal skills through working with The SEED. It should be noted that this effect was especially important for students or people currently employed and less so for retirees. Similarly, Brewis et al. (2010) found that recent graduates under 30 years of age are more inclined to recognize the benefits of volunteering on the development of their interpersonal skills compared with their older counterparts. In a former study, students have reported the greatest impacts of volunteering on their communication skills, willingness to try new things, confidence, and teamwork (Brewis et al. 2010).

One of the main goals of this study was to gauge interest of the current volunteers in a future project related to upcycled food products. Overall, the volunteers showed great enthusiasm toward such an initiative. Those who were not interested in volunteering with the Upcycle Kitchen mostly expressed concerns about their availability or capability to support the initiative. However, one respondent was concerned that the Upcycle Kitchen may serve as a way for businesses to rid themselves of their food waste, rather than provide community benefits. This concern is shared by others writing about the intersection of food rescue and food insecurity (e.g., Riches 2018). The Upcycle Kitchen presents an innovative approach to addressing community goals of reducing food insecurity, employment generation, and reduced stigma while also addressing businesses' (and societal) aims of managing and reducing food waste. The communication of these synergies may be a key task for The SEED as they launch this initiative. This volunteer's feedback therefore provides important information about potential community concerns about the Upcycle Kitchen, and also speaks to the importance of the alignment of values and purpose between a volunteer and the host organization. The feedback of this concerned respondent emphasizes the importance of incorporating volunteer voice, which is defined as the opportunity to provide input and feedback during the decision-making processes (de Cremer et al. 2008). Volunteers without voice may experience feelings of despair, and they may feel that the organization is unfair (Bane 1999). A lack of voice may also lead to volunteers deciding to quit their involvement with the organization (Allen and Mueller 2013).

Among the four main values guiding the Upcycle Kitchen project (Figure 2), tackling food insecurity and reducing the environmental impact of food waste were reported as the most likely to influence the volunteers' willingness to get involved. When considering the recruitment efforts, focusing on these two values in communications materials may increase volunteer recruitment knowing that both values are likely to have deeper meanings to prospective volunteers. The conservation of resources theory suggests that people will strive to build and protect what they value (Hobfoll 1989) and the converse holds true: a volunteer will not be encouraged to participate in an activity that they do not value. Therefore, The SEED would benefit from integrating messages about tackling food insecurity and reducing environmental impacts when using targeted recruitment strategies for volunteers in upcycling-based food projects. Interestingly, Mirosa et al. (2016) note that environmental outcomes were not discussed by most stakeholders they interviewed about food rescue activities; we had prompted respondents on this issue in our survey, which may have influenced their acknowledgement of the environmental outcomes associated with food rescue. The other purposes of the Upcycle 
Kitchen project, which are to create employment and training opportunities for youth facing barriers to employment and to reduce the stigma associated to the consumption of surplus food, also resonated with more than half of the respondents and, therefore, should not be excluded from the conversation. The resonance of all four messages with volunteers suggests that the Upcycle Kitchen will be successful in recruiting skilled volunteers to join this project.

In a report from Community Literacy of Community Literacy of Ontario (2005), 89\% of surveyed volunteers mentioned they felt their agencies were making the most of the skills they had to offer and thought their skills were being used well. Several volunteers, however, identified specific skills (e.g., human resources and teaching) that, in their opinion, could be better used. In order for organizations and agencies to most effectively utilize their volunteers, they must have an overview of the unique and distinctive skill sets of their volunteers. Our study highlighted the broad sets of transferable skills of the individuals volunteering in a food community project that could be useful for integration in the proposed Upcycle Kitchen. Indeed, most of the survey respondents had skills critical to a food preparation and serving environment such as cooking skills, leadership skills or customer service experience. Brayley et al. (2013) have suggested that older volunteers and retirees may be compelled to volunteer by a desire to continue using their accumulated vocational skills. The desire to use accumulated skills may explain why such a high proportion of the surveyed volunteers in a food-related project reported skills which relate to food preparation. Creating an inventory of skills within the volunteer pool is an important step in preparing for new projects, and for recognizing volunteers' skills and interests. This is of particular interest to social enterprises that are thinking of expanding their activities as their current volunteers most likely have a good set of transferable skills applicable to the organization's future endeavors. In a study of elderly volunteers, a common reason for quitting related to feelings of not being able to help as much as they thought they could (Morrow-Howell and Mui 2008). These feelings could be mitigated if the volunteers were given tasks suitable to their skills and abilities, and if the goals and outcomes of the program are clearly communicated. As highlighted by the Corporation for National \& Community Service (2012), skills-based volunteering refers to "leveraging the specialized skills and talents of individuals to strengthen the infrastructure of non-profits, helping them build and sustain their capacity to successfully achieve their missions."

In our study, volunteers reported feeling appreciated for the work they are doing with The SEED, which will likely play a positive role in the retention of the volunteers. For example, one volunteer explained that they felt appreciated through The SEED's current tactics of potluck/meal invitations and thank-you cards. Similarly, other studies have found that volunteers who felt needed and appreciated for their work were more likely to continue volunteering (Bang and Ross 2009; Clary et al. 1992; Phillips and Phillips 2010). Administrators within these organizations would benefit from focusing on volunteers' internal motivations and providing them small non-monetary rewards to retain their volunteers (Phillips and Phillips 2010). By appreciating volunteers' work, administrators will also satisfy the volunteers' need for recognition. Gabbey (2017) suggested tailoring recognition to each volunteer by having them fill out a sheet of all their favorites (i.e., coffee/tea, sports teams, etc.). Then, when it comes time to give recognition to that particular volunteer, the organization can check their sheet and give them something that they would enjoy (Gabbey 2017). However, one study found that promised recognition to volunteers did little to increase the hours donated by volunteers (Fisher and Ackerman 1998). Instead, hours donated by volunteers increased when the volunteer felt their contribution was needed and had little to do with promised recognition (Fisher and Ackerman 1998). Regardless, volunteers are more likely to volunteer more hours when they feel needed, wanted and recognized.

As with any study, the limitations must be acknowledged. Due to a lower than desired response rate, which was similar to that reported in other internal surveys (Anseel et al. 2010), the focus on a small not-for-profit project meant our population size was less than 40 people. Conducting a study on volunteer motivations in such a small population size prevents generalizations to other organizations. At least one other study exploring volunteerism in food rescue enterprises surveyed 
a similar number of respondents (Mirosa et al. 2016). We note Bang and Ross (2009) argument that replication in independent samples provides more evidence than multiple statistics. Despite the small sample size of this research, our conclusions are consistent with many of the findings of other studies of volunteerism (Bang and Ross 2009; Clary et al. 1992; Phillips and Phillips 2010). We believe this paper provides a step towards the understanding of the interests and main values likely to attract volunteers in upcycling-based food projects. This information has value for future researchers, and also for small organizations looking to develop similar projects. Further research on volunteers' interests and main values should be conducted with larger volunteer populations, especially across multiple small organizations.

We note that our study was conducted in a university city with a volunteer population that contains many students. This may have influenced respondents' perceptions of the value of tackling food insecurity and reducing further environmental impact of food waste since these topics are taught throughout many degree programs at the local university.

\section{Conclusions and Implications}

This study investigated volunteers' motivations and perceptions of their work within a food project addressing food insecurity issues in Guelph, Ontario. Food security is a complex issue in high-income countries, and other researchers have pointed to the potential for the incorporation of rescued foods into service provision to lead to a loss of dignity for service users (Caraher and Furey 2017). Thus, the expansion of The SEED's initiatives into the Upcycle Kitchen represents an important moment in their evolution in terms of mission clarity and communication with key stakeholders, including volunteers. Our survey indicates that The SEED's volunteers have a clear sense of the missions guiding this project, and that they are motivated by both the core values of The SEED, as well as their own altruism. Volunteers expressed support for the Upcycle Kitchen, but one respondent was concerned about the intersection of using businesses' wasted food in food insecurity initiatives. This finding indicates that the complexity of using rescued food in food insecurity programming is not just a theoretical or academic concern but is also an important moral issue for those participating in such programs as volunteers. A practical implication of this finding is the importance of on-going dialogue with volunteers about an organization's initiatives, values, and procedures as new initiatives come on board. Such communications can help to ensure continuing alignment between organizational and individual values, as well as create opportunities for volunteer voice.

Our results suggest that some volunteers working with The SEED are similar to traditional volunteers associated with non-profit or charitable sectors, but that many resemble a new type of social enterprise volunteer (e.g., young, skilled volunteers interested in self-development). As more social service and food programming projects transition to social enterprise models, these distinctions become more important for managerial staff as they consider volunteer recruitment, deployment, and retention. Theoretically, this finding suggests that "the hybrid social-economic space" (Munoz et al. 2015) of social enterprises may offer something distinctive to both service users and volunteers. We recommend further studies of such spaces from the perspective of multiple stakeholders involved in the operations of social enterprises.

Finally, this study reinforces the practical importance of volunteer appreciation as an organizational function. Since skill usage and skill development are important considerations for volunteers, volunteer-based organizations may choose to have a short interview process or host a skills survey such as outlined in this study to determine the skills and motivations of volunteers in order to match their skills and experience to a job or task that will be meaningful and purposeful. Regularly expressing appreciation for the time and care that volunteers contribute to a project can help them to see the contribution that they are making to the values-based initiatives that they have chosen to support and may also encourage them to continue to volunteer their energies.

Supplementary Materials: The following are available online at http://www.mdpi.com/2076-0760/9/3/27/s1, Supplementary File 1: Survey Questionnaire: Skill sets and motivations of The SEED's volunteers. 
Author Contributions: S.R., S.M.S., and K.P. worked together to design and develop research methodology and in data acquisition. C.K. assisted with study conceptualization. All authors contributed to the writing and editing of the manuscript. All authors have read and agreed to the published version of the manuscript.

Funding: This research received funding from the University of Guelph Food from Thought Research Assistantship program and the Arrell Food Institute.

Acknowledgments: Our sincere thanks to Kamil Chatila-Amos, Thomas Armitage and Madeline Barber for their assistance in editing and administering the volunteer survey.

Conflicts of Interest: The authors declare no conflict of interest.

\section{References}

Ahn, SangNam, Karon L. Philips, Matthew Lee Smith, and Marcia G. Ory. 2011. Correlates of Volunteering among Aging Texans: The Roles of Health Indicators, Spirituality, and Social Engagement. Maturitas 69: 257-62. [CrossRef] [PubMed]

Allen, Joseph Andrew, and Stephanie L. Mueller. 2013. The Revolving Door: A Closer Look at Major Factors in Volunteers' Intention to Quit. Journal of Community Psychology 41: 139-55. [CrossRef]

Alvord, Sarah H., L. David Brown, and Christine W. Letts. 2004. Social Entrepreneurship and Societal Transformation: An Exploratory Study. Journal of Applied Behavioral Science 40: 260-82. [CrossRef]

Anseel, Frederik, Filip Lievens, Eveline Schollaert, and Beata Choragwicka. 2010. Response Rates in Organizational Science, 1995-2008: A Meta-analytic Review and Guidelines for Survey Researchers. Journal of Business and Psychology 25: 335-49. [CrossRef]

Austin, James, Howard Stevenson, and Jane Wei-Skillern. 2003. Social Entrepreneurship and Commercial Entrepreneurship: Same, Different, or Both? Working Paper Series, No. 04-029; Boston: Harvard Business School.

Bacq, Sophie, and Frank Janssen. 2011. The Multiple Faces of Social Entrepreneurship: A Review of Definitional Issues Based on Geographical and Thematic Criteria. Entrepreneurship E Regional Development 23: 373-403.

Bane, K. Denise. 1999. Effects of Type of Voice on Perceptions of Fairness in Performance Evaluation. Journal of Social Behavior and Personality 14: 75-88.

Bang, Hyejin, and Stephen D. Ross. 2009. Volunteer Motivation and Satisfaction. Journal of Venue and Event Management 1: 61-77.

Bedore, Melanie. 2018. "I was purchasing it; it wasn't given to me": Food Project Patronage and the Geography of Dignity Work. Geographical Journal 184: 218-28. [CrossRef]

Berno, Tracy. 2017. Social Enterprise, Sustainability and Community in Post-Earthquake Christchurch: Exploring the Role of Local Food Systems in Building Resilience. Journal of Enterprising Communities: People and Places in the Global Economy 11: 149-65. [CrossRef]

Bhatt, Siddharth, Jeonggyu Lee, Jonathan Deutsch, Hasan Ayaz, Benjamin Fulton, and Rajneesh Suri. 2018. From Food Waste to Value-Added Surplus Products (VASP): Consumer Acceptance of a Novel Food Product Category. Journal of Consumer Behaviour 17: 57-63. [CrossRef]

Bierma, Thomas J., Guang Jin Guang, and Christy N. Bazan. 2019. Food Donation and Food Safety: Challenges, Current Practices, and the Road Ahead. Journal of Environmental Health 81: 16-21.

Booth, Sue, Christina Pollard, John Coveney, and Ian Goodwin-Smith. 2018. 'Sustainable' Rather Than 'Subsistence' Food Assistance Solutions to Food Insecurity: South Australian recipients' perspectives on traditional and social enterprise models. International Journal of Environmental Research and Public Health 15: 2086. [CrossRef] [PubMed]

Brayley, Nadine, Patricia Obst, Katherine M. White, Ioni M. Lewis, Jeni Warburton, and Nancy M. Spencer. 2013. Exploring the Validity and Predictive Power of an Extended Volunteer Functions Inventory within the Context of Episodic Skilled Volunteering by Retirees. Journal of Community Psychology 42: 1-18. [CrossRef]

Brewis, Georgina, Jennifer Russell, and Clare Holdsworth. 2010. Bursting the Bubble: Students, Volunteering and the Community. Available online: https://www.publicengagement.ac.uk/sites/default/files/publication/ bursting_the_bubble_summary_report.pdf (accessed on 14 January 2020).

Bussell, Helen, and Deborah Forbes. 2006. Understanding the Volunteer Market: The What, Where, Who and Why of Volunteering. International Journal of Nonprofit and Voluntary Sector Marketing 7: 244-57. [CrossRef] 
Caraher, Martin, and Sinéad Furey. 2017. Is it Appropriate to Use Surplus Food to Feed People in Hunger? Short-Term Band-aid to More Deep-Rooted Problems of Poverty. London: Food Research Collaboration, Centre for Food Policy.

Chapnick, Melissa, Ellen Barnidge, Marjorie Sawicki, and Michael Elliott. 2019. Healthy Options in Food Pantries-A Qualitative Analysis of Factors Affecting the Provision of Healthy Food Items in St. Louis, Missouri. Journal of Hunger \& Environmental Nutrition 14: 262-80.

Clary, E. Gill, Mark Snyder, and Robert Ridge. 1992. Volunteers' Motivations: A Functional Strategy for the Recruitment, Placement, and Retention of Volunteers. Nonprofit Management and Leadership 2: 333-50. [CrossRef]

Clary, E. Gill, Mark Snyder, Robert D. Ridge, John Copeland, Arthus A. Stukas, Julie Haugen, and Peter Miene. 1998. Understanding and Assessing the Motivations of Volunteers: A Functional Approach. Journal of Personality and Social Psychology 74: 1516-30. [CrossRef]

Community Literacy of Ontario. 2005. Literacy Volunteers Value Added Research Report. Available online: http://www.communityliteracyofontario.ca/wp/wp-content/uploads/2013/08/volnteer.pdf (accessed on 14 January 2020).

Corporation for National \& Community Service. 2012. Skills Based Volunteering. Available online: https: //www.nationalservice.gov/resources/member-and-volunteer-development/sbv (accessed on 10 January 2020).

de Cremer, David, Ilse Cornelis, and Alain Van Hiel. 2008. To Whom Does Voice in Groups Matter? Effects of Voice on Affect and Procedural Fairness Judgments as a Function of Social Dominance Orientation. The Journal of Social Psychology 148: 61-76. [CrossRef]

Dees, Gregory J. 1998. The Meaning of "Social Entrepreneurship". Kansas City: Kauffman Foundation and Stanford University. Available online: https:/community-wealth.org/content/meaning-social-entrepreneurship (accessed on 13 January 2020).

Demir, Filiz Otay, Ayşe Nil Kireçci, and Şenay Yavuz Görkem. 2019. Deepening Knowledge on Volunteers Using a Marketing Perspective: Segmenting Turkish Volunteers According to Their Motivations. Nonprofit and Voluntary Sector Quarterly 27: 1-27. [CrossRef]

Dennis, Mary Kate, Edward T. Scanlon, and Alicia M. Sellon. 2017. It's a Generosity Loop': Religious and Spiritual Motivations of Volunteers Who Glean Produce to Reduce Food Insecurity. Journal of Religion E Spirituality in Social Work: Social Thought 36: 456-78.

Dimitri, Carolyn, Lydia Oberholtzer, and Andy Pressman. 2016. Urban Agriculture: Connecting Producers with Consumers. British Food Journal 118: 603-17. [CrossRef]

Evans, David, Hugh Campbell, and Anne Murcott. 2012. A Brief Pre-History of Food Waste and the Social Sciences. Sociological Review 60: 5-26. [CrossRef]

Fisher, Robert J., and David Ackerman. 1998. The Effect of Recognition and Group Need on Volunteerism: A Social Norm Perspective. Journal of Consumer Research 25: 262-75. [CrossRef]

Gabbey, Amber Erickson. 2017. Tailor Recognition to Volunteer Needs. The Volunteer Management Report 22: 4.

Gooch, Martin, Delia Bucknell, Dan LaPlain, Benjamin Dent, Peter Whitehead, Abdel Felfel, Lori Nikkel, and Madison Maguire. 2019. The Avoidable Crisis of Food Waste: Technical Report. Value Chain Management International and Second Harvest, Ontario, Canada. Available online: https://secondharvest.ca/research/theavoidable-crisis-of-food-waste/ (accessed on 14 January 2020).

Gordon, Katy, Juliett Wilson, Andrea Tonner, and Eleanor Shaw. 2018. How Can Social Enterprises Impact Health and Well-Being? International Journal of Entrepreneurial Behavior and Research 24: 697-713. [CrossRef]

Government of Ontario. 2013. Impact: A Social Enterprise Strategy for Ontario. Available online: https://www. ontario.ca/page/impact-social-enterprise-strategy-ontario (accessed on 10 January 2020).

Hall, Michael, Alison Andrukow, Cathy Barr, Kathy Brock, Margaret de Wit, Don Embuldeniya, Louis Jolin, David Lasby, Benoît Lévesque, Eli Malinsky, and et al. 2003. The Capacity to Serve-A Qualitative Study of the Challenges Facing Canada's Non-profit and Voluntary Organizations. Ottawa: Canadian Centre for Philanthropy (CCP), Available online: http://sectorsource.ca/sites/default/files/resources/files/capacity_to_serve_english. pdf (accessed on 17 February 2020).

Hecht, Amelie, and Roni A. Neff. 2019. Food Rescue Intervention Evaluations: A Systematic Review. Sustainability 11: 6781. [CrossRef] 
Hibbert, Sally, Maria Piacentini, and Haya Al Dajani. 2003. Understanding Volunteer Motivation for Participation in a Community-based Food Cooperative. International Journal of Nonprofit and Voluntary Sector Marketing 8: 30-42. [CrossRef]

Hobfoll, Stevan. 1989. Conservation of Resources. A New Attempt at Conceptualizing Stress. The American Psychologist 44: 513-24. [CrossRef]

Holweg, Christina, and Eva Lienbacher. 2011. Social Marketing Innovation: New Thinking in Retailing. Journal of Nonprofit \& Public Sector Marketing 23: 307-26.

Hoyos, Angela, and Diego F. Angel-Urdinola. 2019. Assessing International Organizations' Support to Social Enterprise. Development Policy Review 37: O213-O229. [CrossRef]

Hustinx, Lesley, and Els de Waele. 2015. Managing Hybridity in a Changing Welfare Mix: Everyday Practices in an Entrepreneurial Nonprofit in Belgium. Voluntas 26: 1666-89. [CrossRef]

Laufenberg, Günther, Benno Kunz, and Marianne Nystroem. 2003. Transformation of Vegetable Waste into Value Added Products: (A) The Upgrading Concept; (B) Practical Implementation. Bioresource Technology 87: 167-98. [CrossRef]

Luke, Belinda G., and Vien Chu. 2013. Social Enterprise versus Social Entrepreneurship: An Examination of the 'Why' and 'How' in Pursuing Social Change. International Small Business Journal 31: 764-84. [CrossRef]

Lysaght, Rosemary, Klara Jakobsen, and Birgit Granhaug. 2012. Social Firms: A Means for Building Employment Skills and Community Integration. Work 41: 455-63. [CrossRef]

McKay, Fiona H., Kehla Lippi, Matthew Dunn, Bronte C. Haines, and Rebecca Lindberg. 2018. Food-Based Social Enterprises and Asylum Seekers: The Food Justice Truck. Nutrients 10: 756. [CrossRef]

Mirosa, Miranda, Louise Mainvil, Hayley Horne, and Ella Mangan-Walker. 2016. The Social Value of Rescuing Food, Nourishing Communities. British Food Journal 118: 3044-58. [CrossRef]

Morrow-Howell, Nancy, and Ada C. Mui. 2008. Elderly Volunteers: Reasons for Initiating and Terminating Service. Journal of Gerontological Social Work 13: 21-34. [CrossRef]

Mousa, Tamara Y., and Jeanne H. Freeland-Graves. 2017a. Motivations for Volunteers in Food Rescue Nutrition. Public Health 149: 113-19. [CrossRef]

Mousa, Tamara Y., and Jeanne H. Freeland-Graves. 2017b. Organizations of Food Redistribution and Rescue. Public Health 152: 117-22. [CrossRef]

Munoz, Sarah-Anne, Jane Farmer, Rachel Winterton, and Jo Barraket. 2015. The Social Enterprise as a Space of Well-Being: An Exploratory Case Study. Social Enterprise Journal 11: 281-302. [CrossRef]

Nikkel, Lori, Madison Maguire, Martin Gooch, Delia Bucknell, Dan LaPlain, Benjamin Dent, Peter Whitehead, and Abdel Felfel. 2019. The Avoidable Crisis of Food Waste: Roadmap; Second Harvest and Value Chain Management International; Ontario, Canada. Available online: www.SecondHarvest.ca/Research (accessed on 13 February 2020).

O'Donnell, Thomas H., Jonathan Deutsch, Cathy Yungmann, Alexandra Zeitz, and Soloman H. Katz. 2015. New Sustainable Market Opportunities for Surplus Food: A Food System-Sensitive Methodology (FSSM). Food and Nutrition Sciences 6: 883-92. [CrossRef]

Otten, Jennifer J., Sara Diedrich, Katherine Getts, and Christine Benson. 2018. Commercial and Anti-Hunger Sector Views on Local Government Strategies for Helping Manage Food Waste. Journal of Agriculture, Food Systems, and Community Development 8: 55-72. [CrossRef]

Paget, Ally. 2015. Community Supermarkets Could Offer a Sustainable Solution to Food Poverty ... . London: British Aisles. Available online: https:/www.demos.co.uk/files/476_1501_BA_body_web_2.pdf?1427295281 (accessed on 17 February 2020).

Phillips, Laura C., and Mark. H. Phillips. 2010. Volunteer Motivation and Reward Preference: An Empirical Study of Volunteerism in a Large, Not-for-Profit Organization. SAM Advanced Management Journal 75: 12-39.

Popielarski, Jo Anna, and Nancy Cotugna. 2010. Fighting Hunger through Innovation: Evaluation of a Food Bank's Social Enterprise Venture. Journal of Hunger and Environmental Nutrition 5: 56-69. [CrossRef]

R Core Team. 2016. R: A Language and Environment for Statistical Computing. Vienna: R Foundation for Statistical Computing, Available online: https://www.r-project.org/.R (accessed on 17 February 2020).

ReFED. 2016. A Roadmap to Reduce U.S. Food Waste by 20 Percent. Available online: https://www.refed.com/ downloads/ReFED_Report_2016.pdf (accessed on 17 February 2020). 
Reynolds, Christian, John Piantadosi, and John Boland. 2015. Rescuing Food from the Organics Waste Stream to Feed the Food Insecure: An Economic and Environmental Assessment of Australian Food Rescue Operations Using Environmentally Extended Waste Input-Output Analysis. Sustainability 7: 4707-26. [CrossRef]

Riches, Graham. 2018. Food Bank Nations: Poverty, Corporate Charity and the Right to Food. New York: Routledge.

Roy, Michael J., Cam Donaldson, Rachel Baker, and Susan Kerr. 2014. The Potential of Social Enterprise to Enhance Health and Well-Being: A Model and Systematic Review. Social Science E Medicine 123: 182-93.

Roy, Michael J., Rachel Baker, and Susan Kerr. 2017. Conceptualising the Public Health Role of Actors Operating Outside of Formal Health Systems: The Case of Social Enterprise. Social Science E Medicine 172: 144-52.

Sagawa, Shirley, and Eli Segal. 2000. Common Interest, Common Good: Creating Value Through Business and Social Sector Partnership. California Management Review 42: 105-22. [CrossRef]

Sedlmeier, Regina, Meike Rombach, and Vera Bitsch. 2019. Making Food Rescue Your Business: Case Studies in Germany. Sustainability 11: 5101. [CrossRef]

Sinha, Maire. 2015. Volunteering in Canada, 2004 to 2013. Statistics Canada. Available online: https: //www150.statcan.gc.ca/n1/pub/89-652-x/89-652-x2015003-eng.htm (accessed on 14 January 2020).

Staicu, Daniela. 2018. Financial Sustainability of Social Enterprise in Central and Eastern Europe. Processings of the International Conference on Business Excellence 12: 907-17. [CrossRef]

Tarasuk, Valerie, Andy Mitchell, and Naomi Dachner. 2016. Household Food Insecurity in Canada, 2014; Toronto: Research to Identify Policy Options to Reduce Food Insecurity (PROOF). Available online: https://proof. utoronto.ca/wp-content/uploads/2016/04/Household-Food-Insecurity-in-Canada-2014.pdf (accessed on 14 January 2020).

Vecina, María L., and Daniela Marzana. 2019. Motivations for Volunteering: Do Motivation Questionnaires Measure What Actually Drives Volunteers? Testing, Psychometrics, Methodology in Applied Psychology 26: 573-87.

Warburton, Jeni, and Rachel Winterton. 2017. A far greater sense of community: The impact of volunteer behaviour on the wellness of rural older Australians. Health \& Place 48: 132-38.

Warburton, Jeni, Melanie Oppenheimer, and Gianna Zappalà. 2004. Marginalizing Australia's Volunteers: The Need for Socially Inclusive Practices in the Non-Profit Sector. Australian Journal on Volunteering 9: 33-40.

Wills, Benjamin. 2017. Eating at the limits: Barriers to the Emergence of Social Enterprise Initiatives in the Australian Emergency Food Relief Sector. Food Policy 70: 62-70. [CrossRef]

Wilson, John. 2012. Volunteerism Research: A Review Essay. Nonprofit and Voluntary Sector Quarterly 41: 176-212. [CrossRef]

Wu, Joseph T., Wing Lo, and Elaine S. C. Liu. 2009. Psychometric Properties of the Volunteer Functions Inventory with Chinese Students. Journal of Community Psychology 37: 769-80. [CrossRef]

Yanagisawa, Hisayo, and Hisatak Sakakibara. 2008. Factors Affecting Satisfaction Levels of Japanese Volunteers in Meal Delivery Services for the Elderly. Public Health Nursing 25: 471-79. [CrossRef] [PubMed]

Yeung, Anne Birgitte. 2004. The Octagon Model of Volunteer Motivation: Results of a Phenomenological Analysis. International Journal of Voluntary and Nonprofit Organizations 15: 21-46. [CrossRef]

Zappalà, G. 2001. From 'Charity' to 'Social Enterprise': Managing Volunteers in Public-Serving Nonprofits. Australian Journal on Volunteering 6: 41-49.

(C) 2020 by the authors. Licensee MDPI, Basel, Switzerland. This article is an open access article distributed under the terms and conditions of the Creative Commons Attribution (CC BY) license (http://creativecommons.org/licenses/by/4.0/). 